\title{
Desk-top computer in the clinical laboratory linked to automatic multichannel biochemistry analysers
}

\author{
Lars Funding and Yngve Bergqvist \\ Department of Clinical Chemistry, Falu Central Hospital, S-791 82 Falun, Sweden
}

\section{Introduction}

New analytical instruments are continuously being introduced into the clinical laboratory. Although these instruments are becoming more and more sophisticated they have many drawbacks: inflexible result print-outs, meagre analytical-method control reports and no statistics for billing purposes and cost evaluation.

Due to the continued advancements in computer technology, relatively inexpensive microcomputers have become available for use in the laboratory $[1,2]$.
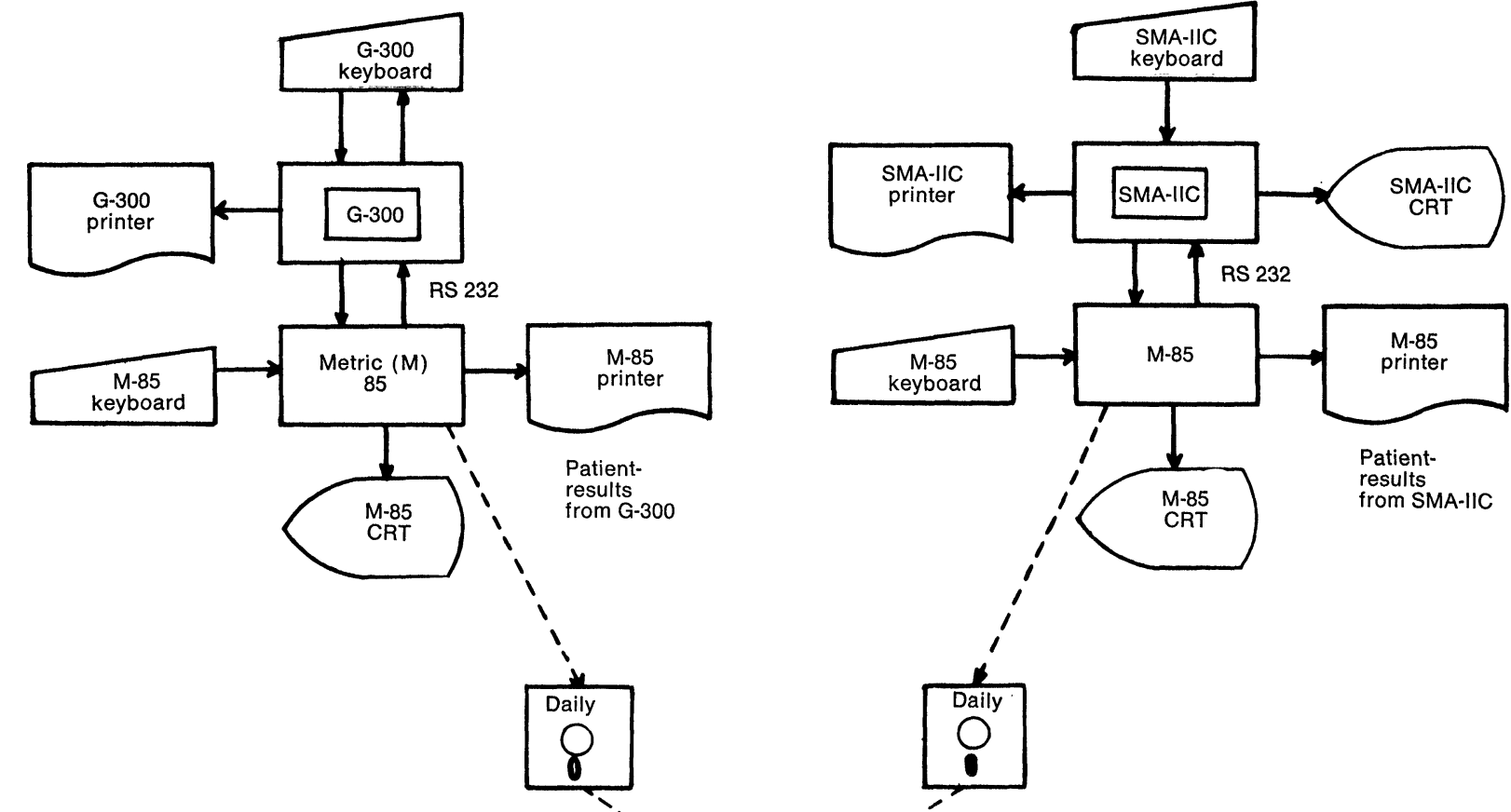
regular use in the authors' laboratory since May 1981. The system's prime purpose is to collect results from multichannel analysers, such as the G-300 (Greiner) and SMA-IIC (Technicon), and to store them on a discette. The collected data are later sorted, statistically processed and listed.

\section{Equipment and method}

The system hardware consists of three Metric 85 microcomputers. Each has a Zilog Z 80 CPU, 64 kilobytes RAM, two

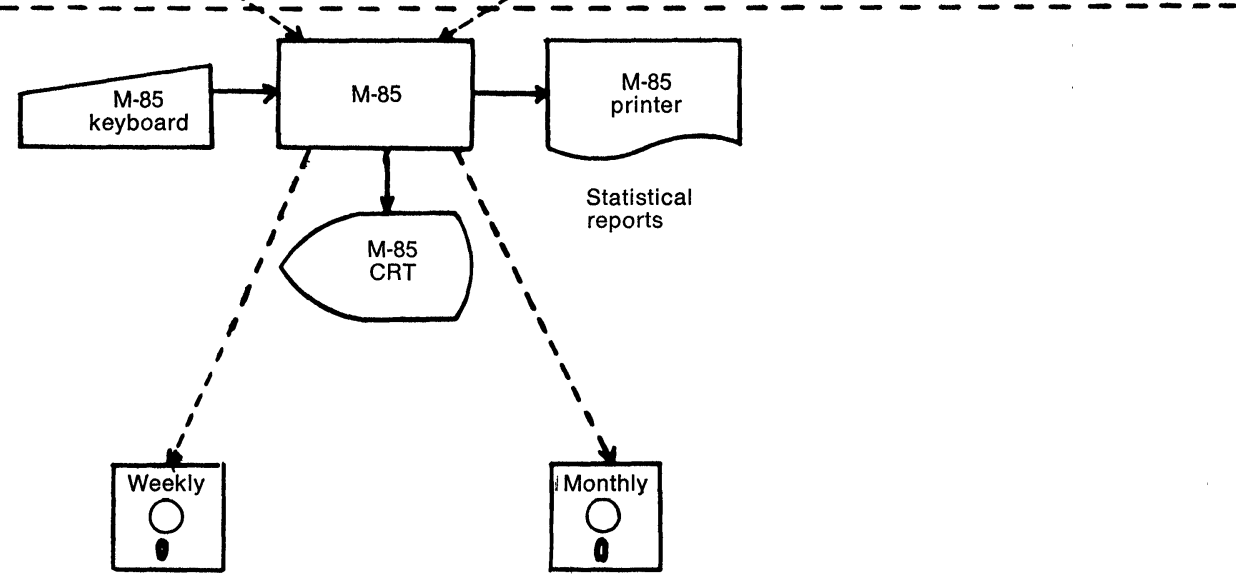

Figure 1. Schematic outline of the desk-top computer system linkage to the G-300 and SMA-IIC multichannel analysers. 
Micropolis mini floppy-disc drives with storage capacities of 315 kilobytes/drive, a visual display screen and a keyboard. The hardware, which cost less than $111000 \mathrm{Sw}$. kr. (US \$ 18000), was supplied by Scandia Metric AB of Solna, Sweden. One microcomputer is connected to a Greiner G-300 analyser via a RS 232 serial interface; another is connected in a similar manner to a Technicon SMA-IIC analyser.

Data are transferred from the analysers to the computers in predefined blocks. In the event of data loss the computer can request repeated transmission of the data block. Two Tally 1612 matrix printers are used to print-out the results from the analysers.

The third Metric 85 is used for statistical reports and is able, in an emergency, to replace one of the computers connected to the multichannel analysers.

The programs, which were written in BASIC, were developed in collaboration with Infax Data of Spånga, Sweden.

\section{Results and discussion}

The data system was built to serve the needs of small and medium-size laboratories where routine analytical work is organized around bio-analytical multichannel analysers. A schematic outline of the authors' system is shown in figure 1 .

The computer system has the following features: automatic

GREINER $\quad 6-300: 1$

KVALITETSKONTROLL

DATUA : $81-10-31$

ANALYS: 6 S-ASAT

ENHET: UKAT/L

KONTROLLLR: 2 AUTONORH 72

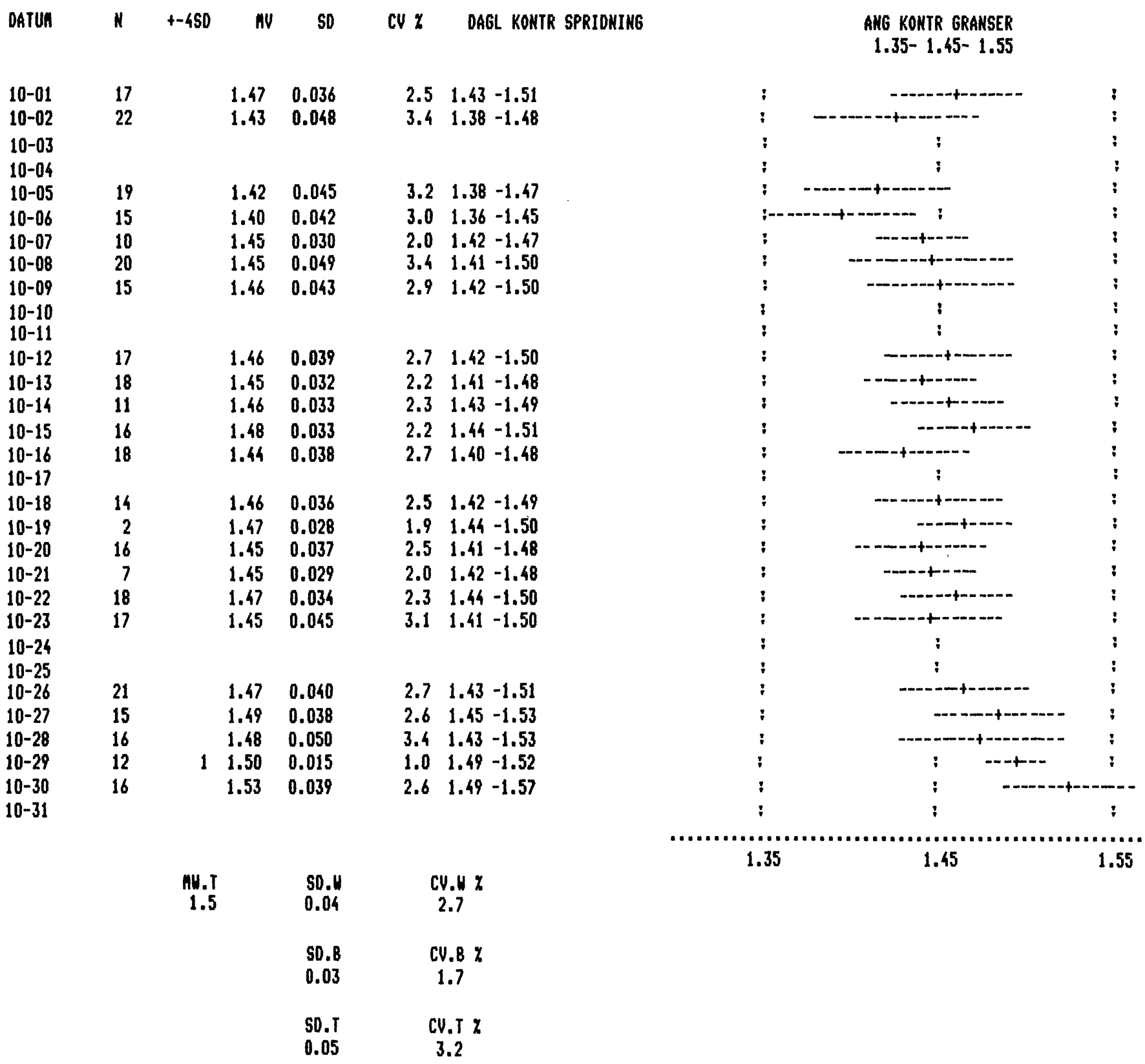

Figure 2. Quality-control print-out for ASAT from the G-300 over one month. 
Ackunulersd statistik $\quad 6-300: 1$

fr $0=81-10-01+0: 81-10-30$

KONTO CA KREA UREA BIL ALP ASAT ALAT L LO GGT ALB KOL TRI AHY

$\begin{array}{rrrrrrrrrrrrrr}37210 & 0 & 7 & 26 & 20 & 16 & 142 & 142 & 115 & 1 & 25 & 0 & 0 & 14 \\ 37313 & 0 & 27 & 0 & 27 & 25 & 120 & 119 & 94 & 0 & 1 & 0 & 0 & 72 \\ 37510 & 0 & 0 & 0 & 26 & 24 & 24 & 24 & 23 & 0 & 0 & 0 & 0 & 8\end{array}$

$\begin{array}{rrrrrrrrrrrrrr}50106 & 0 & 4 & 1 & 171 & 163 & 166 & 169 & 165 & 1 & 13 & 0 & 0 & 118 \\ 50110 & 0 & 3 & 1 & 7 & 7 & 9 & 9 & 9 & 0 & 0 & 0 & 0 & 0 \\ 50111 & 0 & 0 & 0 & 3 & 22 & 40 & 40 & 21 & 0 & 0 & 0 & 0 & 0\end{array}$

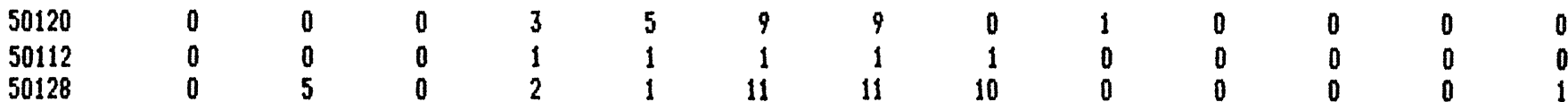

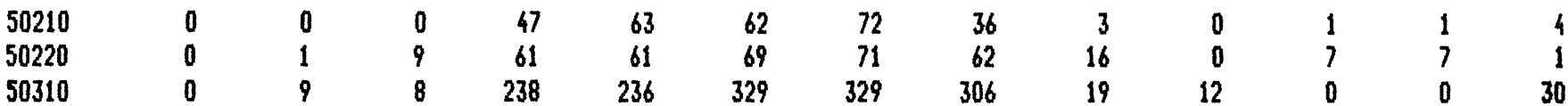

$\begin{array}{lllllllllllllll}50320 & 0 & 0 & 0 & 24 & 24 & 203 & 203 & 184 & 3 & 0 & 0 & 0 & 1\end{array}$

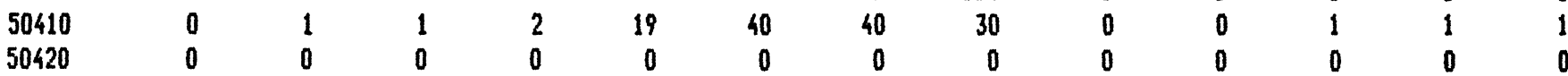

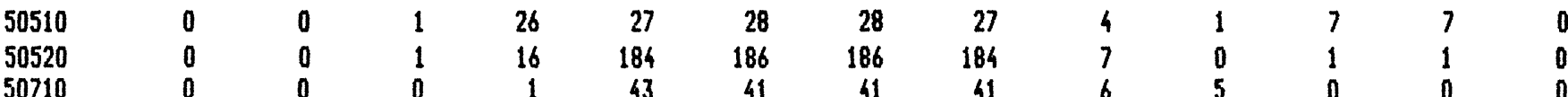

$\begin{array}{lllrllllllllll}50720 & 0 & 0 & 6 & 2 & 2 & 3 & 3 & 0 & 0 & 1 & 0 & 0 & 0 \\ 51810 & 0 & 0 & 13 & 0 & 1 & 4 & 4 & 3 & 0 & 1 & 0 & 0 & 0 \\ 51820 & 0 & 0 & 0 & 1 & 0 & 4 & 4 & 4 & 0 & 0 & 0 & 0 & 0\end{array}$

$\begin{array}{llllllllllllll}51820 & 0 & 1 & 0 & 2 & 2 & 2 & 2 & 2 & 0 & 0 & 0 & 0 & 0\end{array}$

$\begin{array}{llllllllllllll}52110 & 0 & 0 & 0 & 32 & 32 & 32 & 32 & 32 & 0 & 0 & 0 & 0 & 0\end{array}$

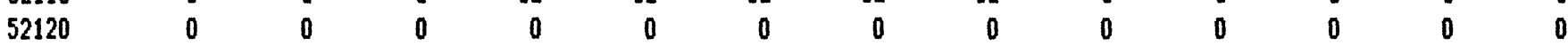

$\begin{array}{llllllllllllll}52128 & 0 & 0 & 0 & 10 & 11 & 11 & 11 & 11 & 0 & 0 & 0 & 0 & 0\end{array}$

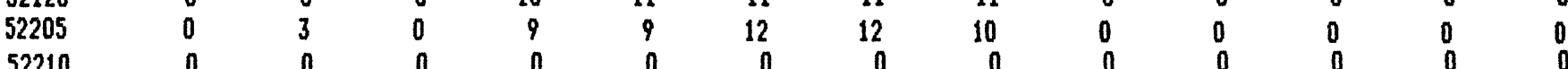

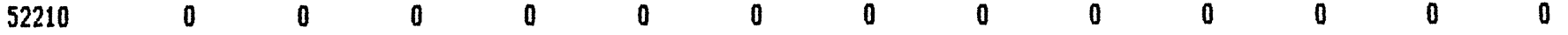

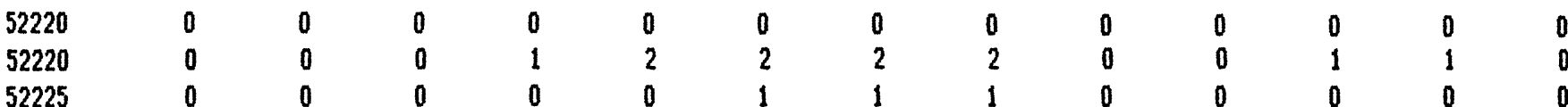

$\begin{array}{lllllllllllll}52410 & 0 & 0 & 0 & 1 & 0 & 7 & 7 & 5 & 0 & 0 & 0 & 0 \\ 52420 & 0 & 0 & 0 & 27 & 27 & 0\end{array}$ $\begin{array}{rrrrrrrrrrrrr}52420 & 0 & 0 & 0 & 27 & 27 & 27 & 27 & 27 & 1 & 0 & 0 & 0 \\ 52710 & 0 & 5 & 3 & 42 & 43 & 50 & 50 & 45 & 14 & 0 & 0 & 0\end{array}$

$\begin{array}{rrrrrrrrrrrrrr}52720 & 0 & 0 & 0 & 2 & 3 & 3 & 3 & 3 & 0 & 0 & 0 & 0 & 0\end{array}$

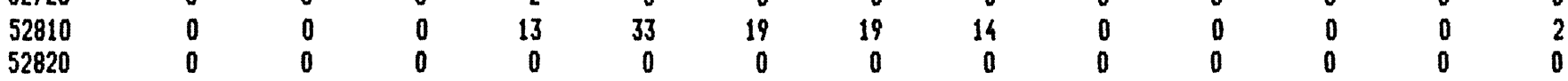

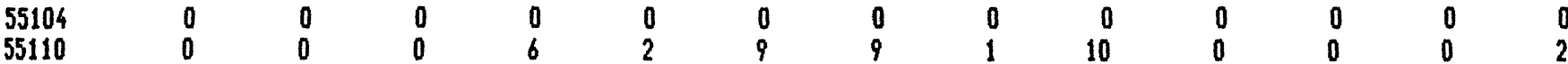

55120

Figure 3. Administrative statistics over a monthly period. 


\begin{tabular}{|c|c|c|c|c|c|c|c|c|}
\hline 350 FERSON & NR 1111111 & & $811030-$ & 350 PEKSON & NR 11 & 1111111 & & $-811030--$ \\
\hline LOPNR. 001 & & & $\begin{array}{l}11111111 \\
\text { HEMOLYS }\end{array}$ & LOPNR. 001 & & & & $\begin{array}{l}111111111 \\
\text { HE HOLYS }\end{array}$ \\
\hline ANALYS & REF & ENHET & SUAR & ANALYS & & REF & ENHET & SUAR \\
\hline S-NATKIUA & $136-147$ & mmol/l & 149.* & S-CALCIUA & 2.15 & $5-2.60$ & MMOL/L & 2.50 \\
\hline S-KALIUM & $3.5-4.8$ & mmol/l & $5.2 *$ & S-KREATININ & 56 & -126 & UMOL/L & -- \\
\hline S-KL.ORIDER & $97-111$ & mmol & 110. & S-UREA & 3.6 & -8.9 & MMOL/L & -- \\
\hline S-KREATININ & $\begin{array}{ll}56 & -126\end{array}$ & umo & 120. & S-BILIRUBIN & 3 & -20 & UMOL/L & -- \\
\hline S-TOT.FROT. & $63-83$ & & 80. & S-ALF & 1.2 & -5.2 & UKAT/L & $6.5 *$ \\
\hline S-CALCIUM & $2.15-2.60$ & mmol/ & 2.50 & S-ASAT & 0.15 & $5-0.70$ & UKAT/L & $0.85 *$ \\
\hline S-FOSFAT & $0.80-1.60$ & mmol/l & 1.05 & S-ALAT & 0.15 & $5-0.70$ & UKAT/L & $1.15 *$ \\
\hline S-URAT & $140-480$ & whol/l & 165 & $S-L D$ & 0 & -8.0 & UKAT/L & -- \\
\hline & - & & - & S-GAMMA-GT & & - & UKAT/L & -- \\
\hline & - & & -- & S-ALBUMIN & 40.0 & $0-52.0$ & $G / L$ & 45.0 \\
\hline & - & & -- & S-KOLEST. & 3.6 & -8.8 & MMOL/L & -- \\
\hline & - & & - & S-TRIGLY. & 0.6 & -2.6 & MMOL/L & -- \\
\hline & - & & -STATUS & S-AMYLAS & 1.2 & -5.0 & UKAT/L & -- \\
\hline & - & & - & & & - & & - \\
\hline
\end{tabular}

Figure 4. Patient result labels for the SMA-IIC and G-300 generated by the desk-top computer.

on-line data collection; reporting of patient results on selfadhesive labels; registration and retrieval of data from disc using patient ID; the possibility of manual data entry from other analysers and data editing through the computer's keyboard; data security (passwords prevent unauthorized access to data); administrative statistics of analyses ordered by each ward; and generation of quality-control statistics for five different controls-these can be supplied both daily and monthly. Figure 2 shows a typical monthly quality-control report.

In the process of converting the data the program checks for error messages from the G-300 and the SMA-IIC (channel difficulties, out of instrument range etc.), and it looks for abnormal patient values and at some sample aspects (haemolytic, icteric, lipaemic). The system's capacity on one computer is up to 750 different patients/day at a maximum of 14 analyses/ patient. The system can administrate 72 different ward numbers on a special monthly discette and 5500 patients with 14 analyses/patient on a special weekly discette. Figure 3 is an example of the results that would be available monthly.

All laboratory requests are entered on either the G-300 or the SMA-IIC's keyboard. Each patient has an identification number of 12 digits: the first three digits are a ward number for administrative statistics and the other nine digits are the .patient's personal identification number which includes the birth date. After entering the identification number the requested analyses are entered via the keyboard. This data- or request-routine does not need any special personnel for the data input step. At the end of each day the data are transferred to the monthly and the weekly discette.

The printer, which is connected to the M-85 computer, provides results on a self-adhesive label. The ward code and patient's ID are printed, together with the date of each analysis. For each analysis its name, reference limits and units are printed. Figure 4 is an example of a printed label.

The programs were written in BASIC and are therefore readily adaptable to other computer systems and to other multichannel analysers. Infax Data has recently modified and adapted the program to a Hitachi 705 analyser (Boehringer Mannheim, Scandinavia of Stockholm, Sweden) in a Swedish hospital.

\section{References}

1. Bishop, C., Clinical Chemistry, 27 (1981), 704.

2. Undrill, P. E., Stroud, R. E. and PAterson, N., Clinical Chemistry, 25 (1979), 466. 


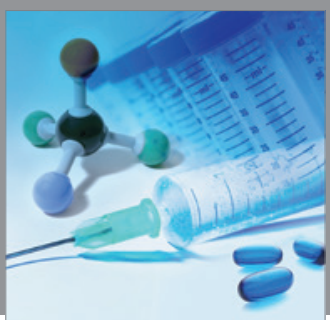

International Journal of

Medicinal Chemistry

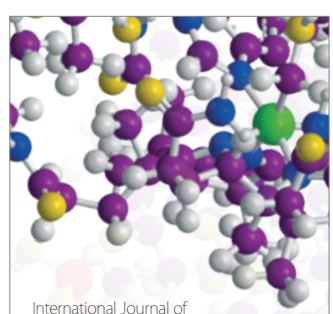

Carbohydrate Chemistry

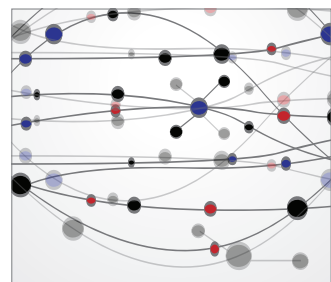

The Scientific World Journal
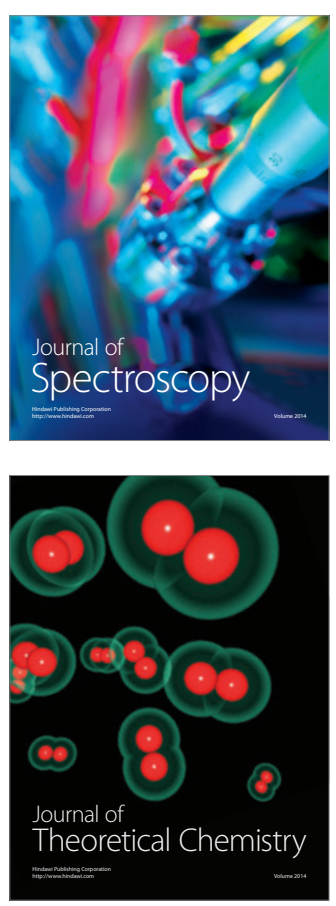
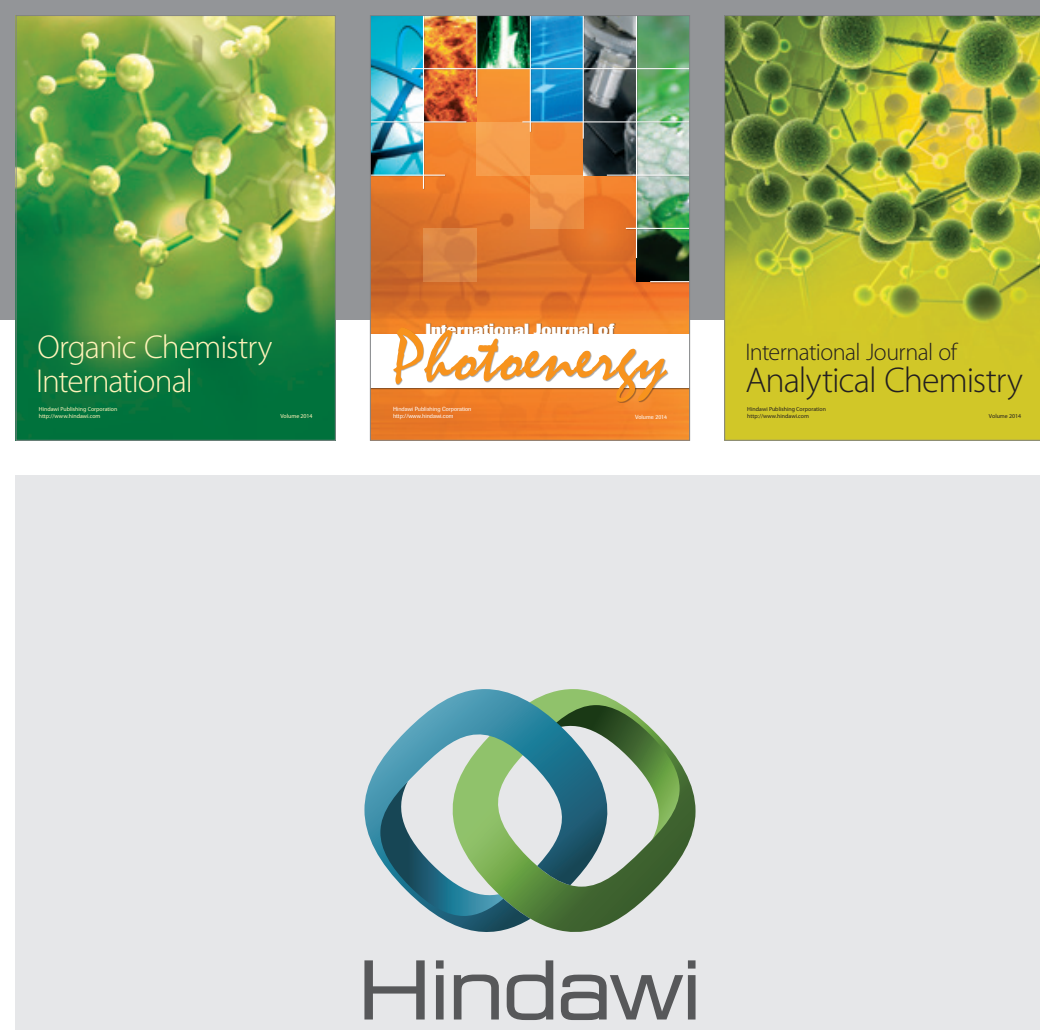

Submit your manuscripts at

http://www.hindawi.com
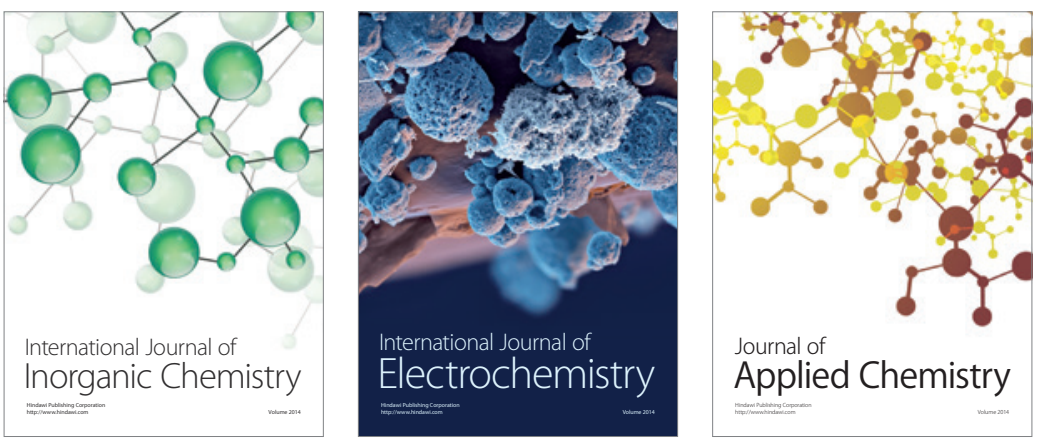

Journal of

Applied Chemistry
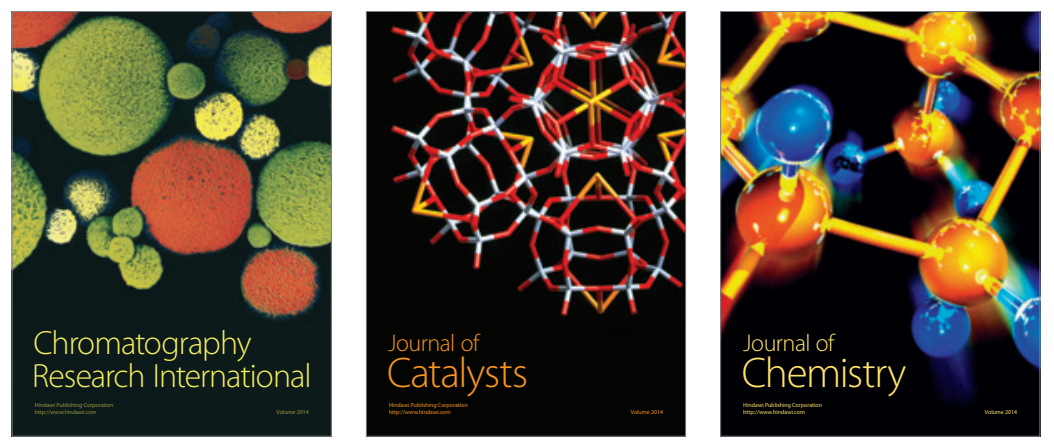
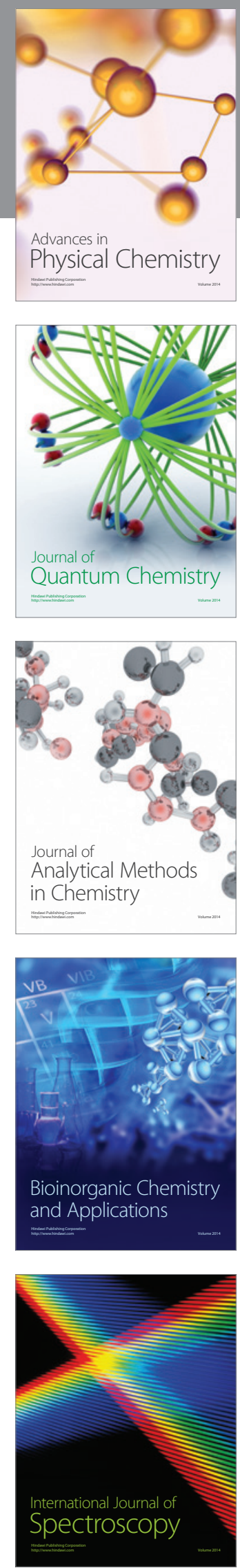